\title{
elsevier_PDST_7496
}

\section{Thermo and photo-oxidation of functionalized metallocene high density polyethylene: Effect of hydrophilic groups}

M.U. de la Orden ${ }^{\mathrm{a}, \mathrm{b}, *}$

mariula@ucm.es

J.M. Montes ${ }^{\mathrm{C}}$

J. Martínez Urreaga $a^{\mathrm{b}, \mathrm{c} \text {, The surname is Martinez Urreaga }}$

A. Bento ${ }^{d}$

M.R. Ribeiro ${ }^{d}$

E. Pérez ${ }^{\mathrm{e}}$

M.L. Cerrada $a^{\mathrm{e}, * *}$

mlcerrada@ictp.csic.es

aUniversidad Complutense de Madrid, Facultad de Óptica y Optometría, Dpto. Química Orgánica 1, Madrid 28037, Spain

bPolymers, Characterization and Applications Research Group, Spain

‘Universidad Politécnica de Madrid, ETSI Industriales, Dpto. Ingeniería Química Industrial \& Medio Ambiente, E-28006 Madrid, Spain

dInstituto Superior Técnico, Universidade Técnica de Lisboa, 1049-001 Lisboa, Portugal

eInstituto de Ciencia y Tecnología de Polímeros (ICTP-CSIC), 28006 Madrid, Spain

*Corresponding author. Universidad Complutense de Madrid, Facultad de Óptica y Optometría, Dpto. Química Orgánica 1, Madrid 28037, Spain.

**Corresponding author.Instituto de Ciencia y Tecnología de Polímeros (ICTP-CSIC), 28006 Madrid. Spain

\section{Abstract}

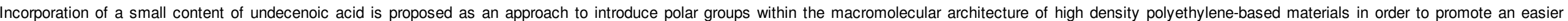

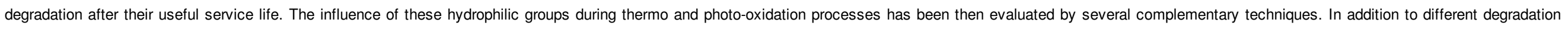

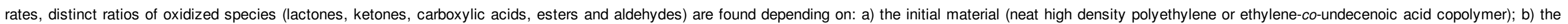

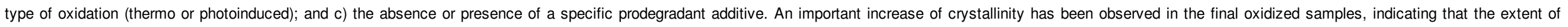
degradation is rather significant.

Keywords: Undecenoic acid; Polyethylene; Oxidation processes; Prodegradant; FTIR; Crystallinity

\section{Introduction}

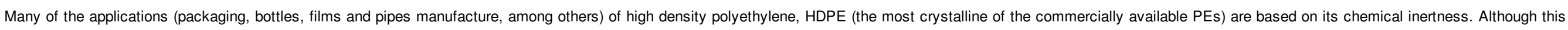

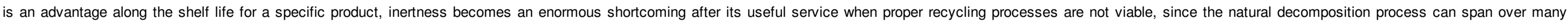

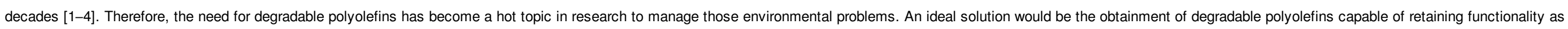




\section{elsevier_PDST_7496}

commodity plastics for the required service life but whose degradation leads to non-toxic end products in a disposal environment.

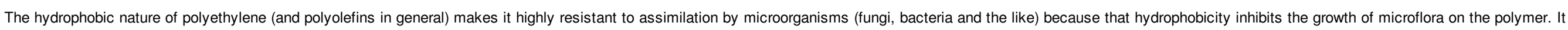

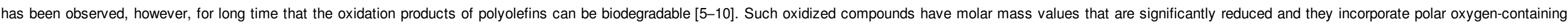

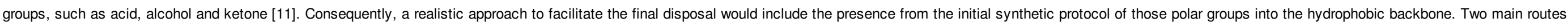

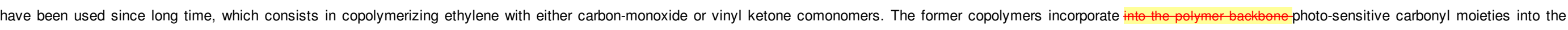

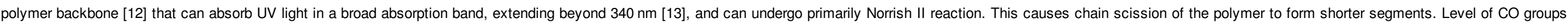
incorporated into the polymer chains must be limited to below $2 \%$ and some products from Dow Chemical, DuPont and Union Carbide are commercially available.

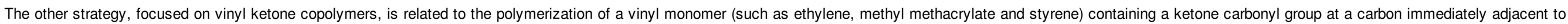

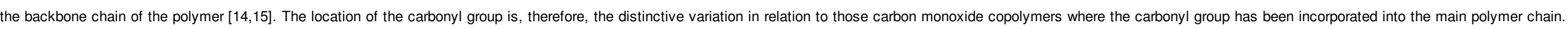

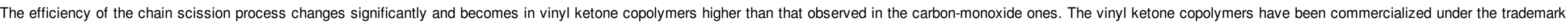
of Ecolyte [12].

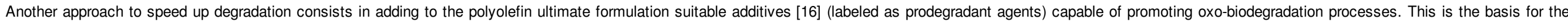

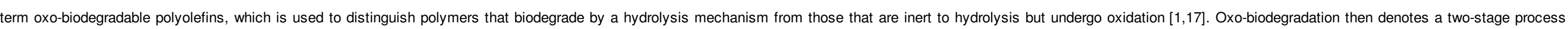

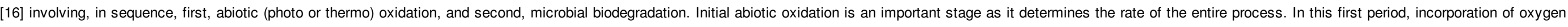

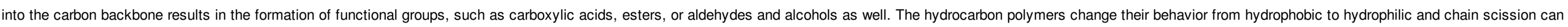
be initiated, allowing this fragmented polymer to absorb water. In the second stage, these fragments are intended to be biodegradable by microorganisms in soil or during composting.

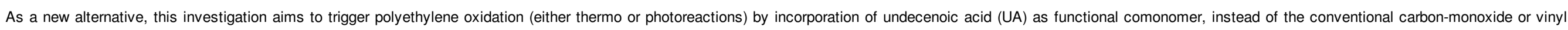

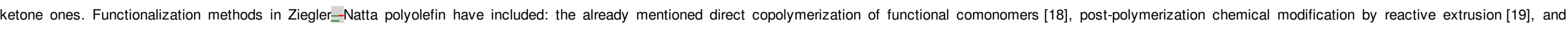

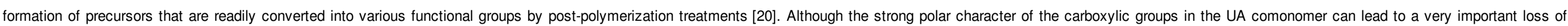

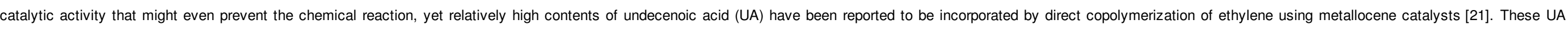
groups have been selected instead of traditional comonomers owing to the recent interest of their use as compatibilizer agent in hybrid polymeric materials [22,23].

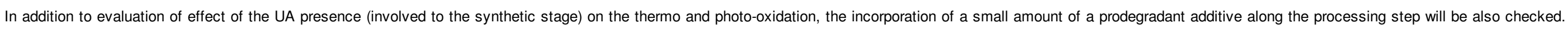

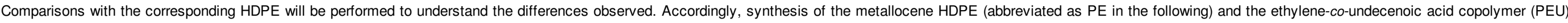

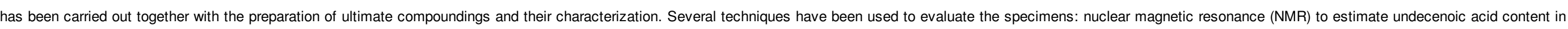

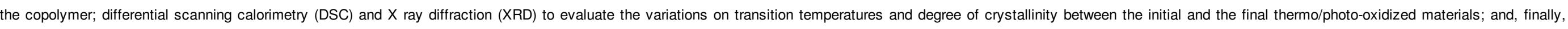
Fourier Transform infrared (FTIR) spectroscopy and thermogravimetric analysis for monitoring the thermo and photo-oxidation processes.

\section{Experimental part}

\subsection{Materials}

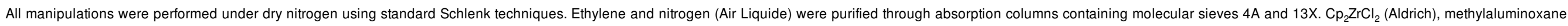
(MAO, $10 \mathrm{wt}$ \% in toluene solution, Albemarle), and undecenoic acid (UA, Aldrich) were used as received. Toluene (Petrogal) was distilled over sodium under a dry nitrogen atmosphere, using benzophenone as indicator.

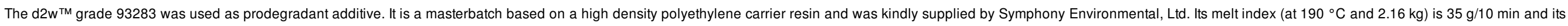
density $0.925 \mathrm{~g} / \mathrm{cm}^{3}$ as indicated by its technical data sheet.

\subsection{Polymerization}

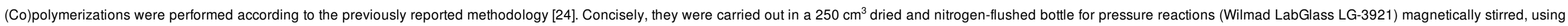




\section{elsevier_PDST_7496}

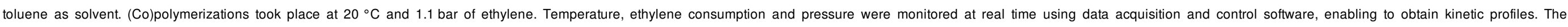

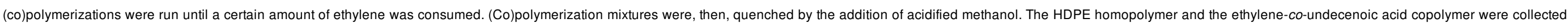
and washed twice with methanol before drying.

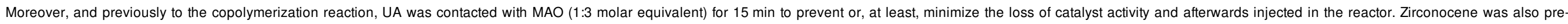

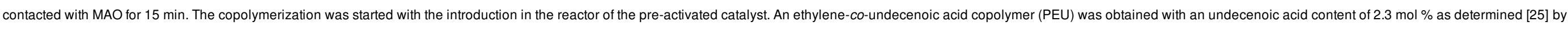
${ }^{1} \mathrm{H}$ NMR

\subsection{Ultimate pristine materials}

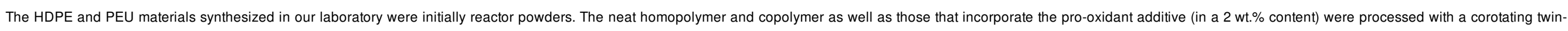

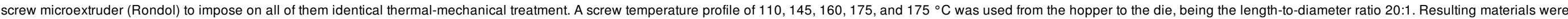

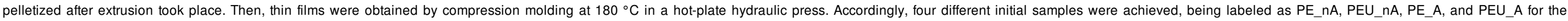
homopolymer and copolymer without and with additive, respectively. In addition, T or P is appended to a given name, referring to thermo or photo-oxidized samples, respectively.

\subsection{Polymer characterization}

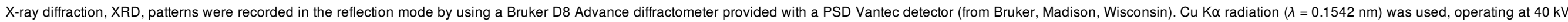

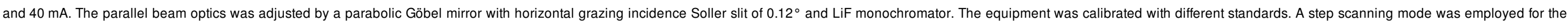
detector. The diffraction scans were collected within the range of $2 \theta=1-43^{\circ}$, with a $2 \theta$ step of $0.024^{\circ}$ and $0.2 \mathrm{~s}$ per step.

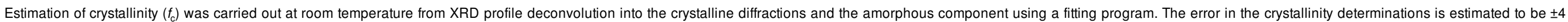
units.

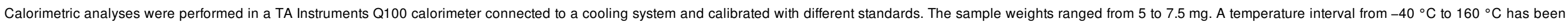
studied and the used heating rate was $10^{\circ} \mathrm{C} / \mathrm{min}$. For crystallinity determinations, a value of $290 \mathrm{~J} / \mathrm{g}$ has been taken as the enthalpy of fusion of a perfectly crystalline material [26,27].

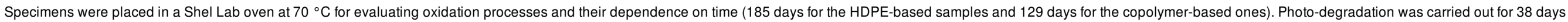

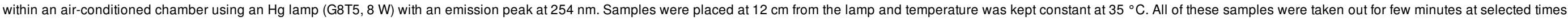
to perform FTIR measurements along both processes.

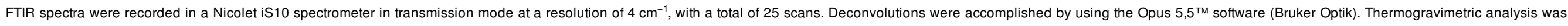
carried out using a TA Instruments TGA2050 thermobalance. Samples of $\sim 10 \mathrm{mg}$ were heated at $10{ }^{\circ} \mathrm{C} / \mathrm{min}$ from room temperature to $900{ }^{\circ} \mathrm{C}$ in dry nitrogen $(30 \mathrm{~cm} / \mathrm{min})$.

\section{Results and discussion}

\subsection{Structural details and phase transition location}

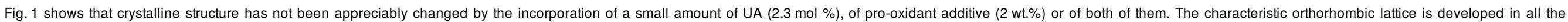

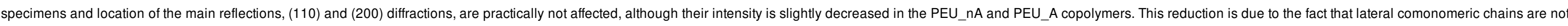

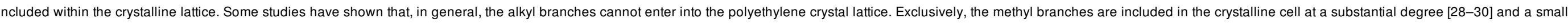
proportion of ethyl ones has been also found in crystalline environments [31,32]. 


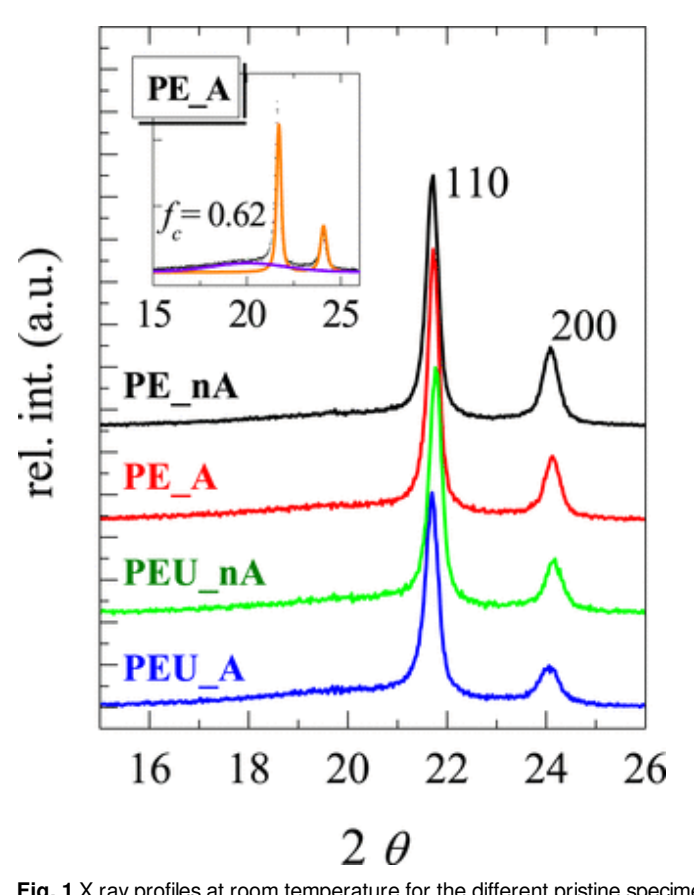

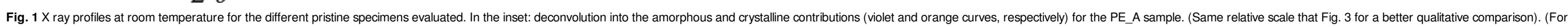
interpretation of the references to color in this figure legend, the reader is referred to the web version of this article.)

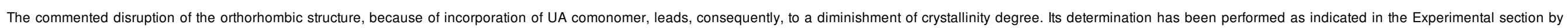

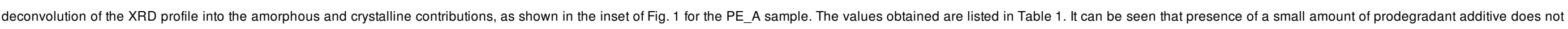
affect much the crystallinity exhibited by the as-obtained initial specimens (i.e., the ones just extruded and compressed-molded samples) from the homopolymer and copolymer.

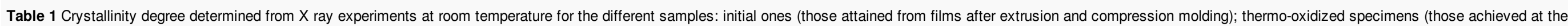
end of the thermo-oxidation process occurred within an oven at $70{ }^{\circ} \mathrm{C}$ for 185 days); and, UV oxidized samples (those obtained at the end of the UV irradiation process at $35{ }^{\circ} \mathrm{C}$ for 38 days).

\begin{tabular}{|c|c|c|c|}
\hline Sample & Initial $f_{\mathrm{c}} \times \mathrm{RD}$ & Thermo-oxidized $f_{c}^{\times R D}$ & Photo-oxidized $f_{c}^{\times R D}$ \\
\hline PE_nA & 0.63 & 0.83 & 0.84 \\
\hline PE_A & 0.62 & 0.81 & 0.80 \\
\hline PEU_nA & 0.58 & 0.76 & 0.72 \\
\hline PEU_A & 0.56 & 0.76 & 0.72 \\
\hline
\end{tabular}

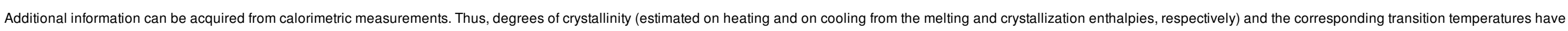

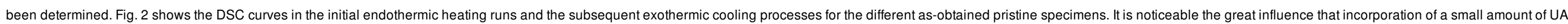

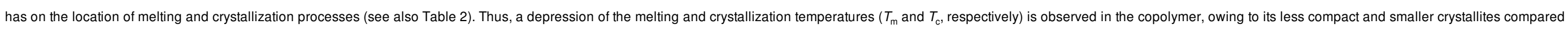

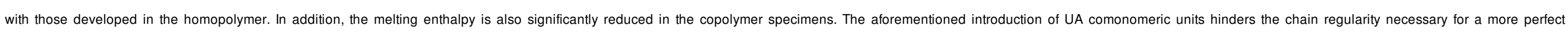

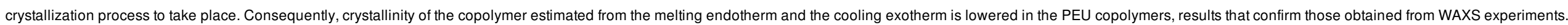




\section{elsevier_PDST_7496}

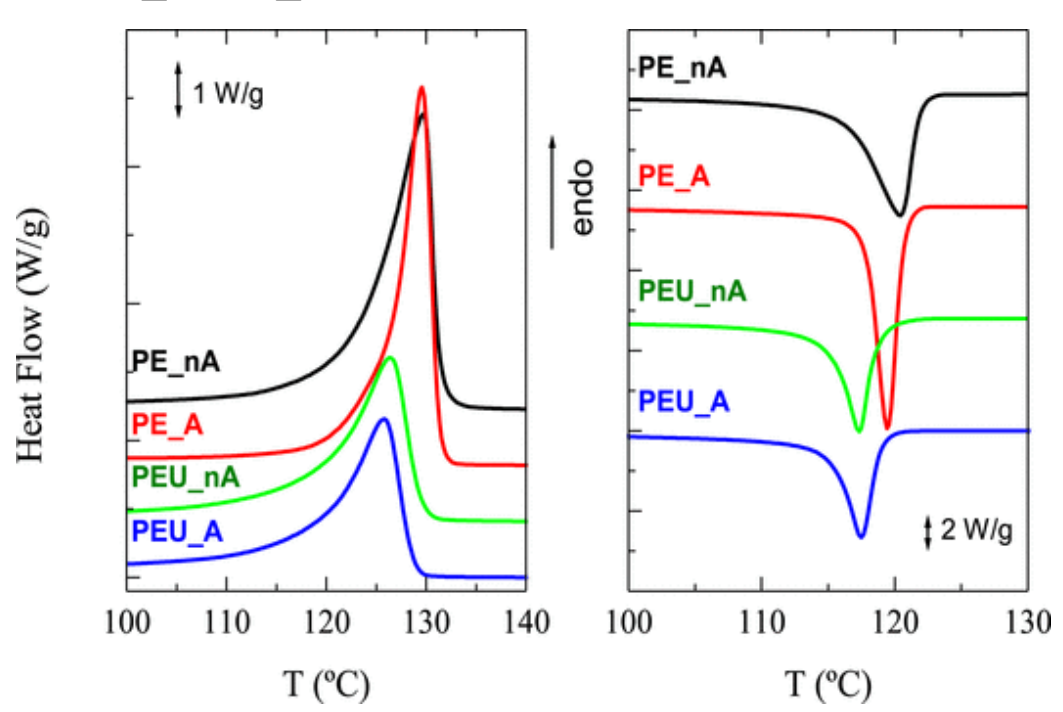

Fig. 2 Calorimetric curves for the four initial specimens evaluated: first melting runs (left plot) and subsequent cooling processes (right plot).

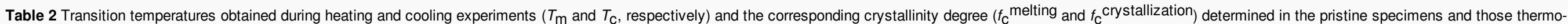
oxidized $(T)$

\begin{tabular}{|c|c|c|c|c|}
\hline Samples & $T_{\mathrm{m}}\left({ }^{\circ} \mathrm{C}\right)$ & $f_{\mathrm{c}}^{\text {melting }}$ & $T_{\mathrm{c}}\left({ }^{\circ} \mathrm{C}\right)$ & $f_{\mathrm{c}}^{\text {crystallization }}$ \\
\hline PE_nA & 129.5 & 0.71 & 120.5 & 0.73 \\
\hline PE_A & 129.5 & 0.68 & 119.5 & 0.71 \\
\hline PEU_nA & 126.5 & 0.53 & 117.5 & 0.60 \\
\hline PEU_A & 126.0 & 0.58 & 117.5 & 0.59 \\
\hline PE_nA_T & 129.5 & 0.82 & 120.0 & 0.74 \\
\hline PE_A_T & 129.0 & 0.76 & 119.5 & 0.68 \\
\hline PEU_nA_T & 127.0 & 0.64 & 118.0 & 0.62 \\
\hline PEU_A_T & 127.5 & 0.71 & 117.5 & 0.65 \\
\hline
\end{tabular}

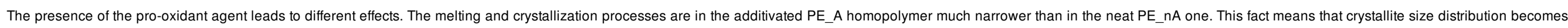

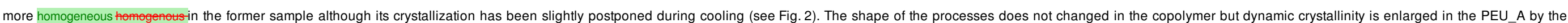
presence of the additive.

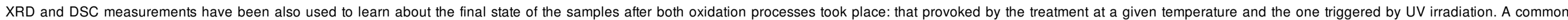

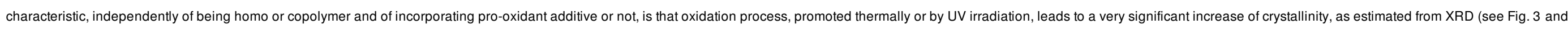

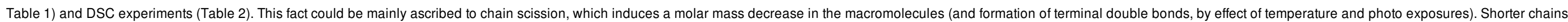
can thus crystallize in a larger extent. 


\section{elsevier_PDST_7496}

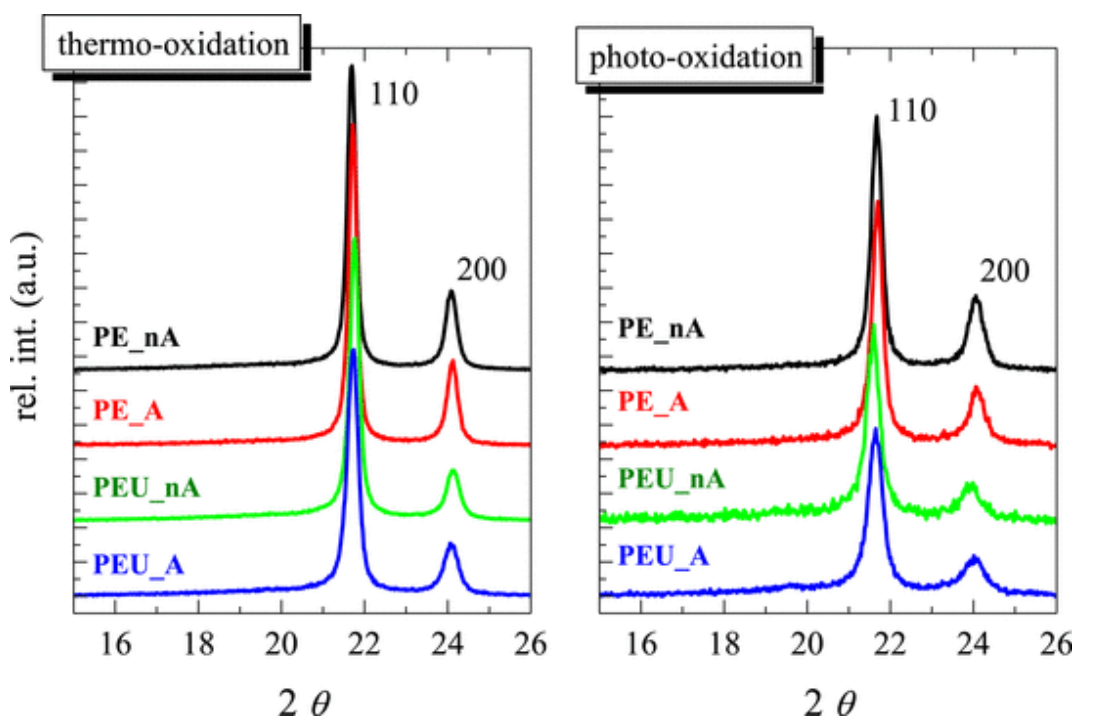

Fig. $3 \mathrm{X}$ ray profiles at room temperature for the different thermo and photo-oxidized specimens (left and right, respectively).

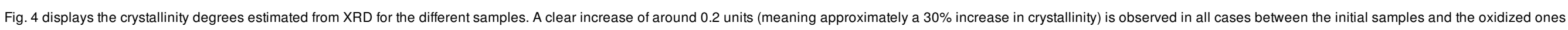
(with very similar values for thermo- and photo-oxidation).

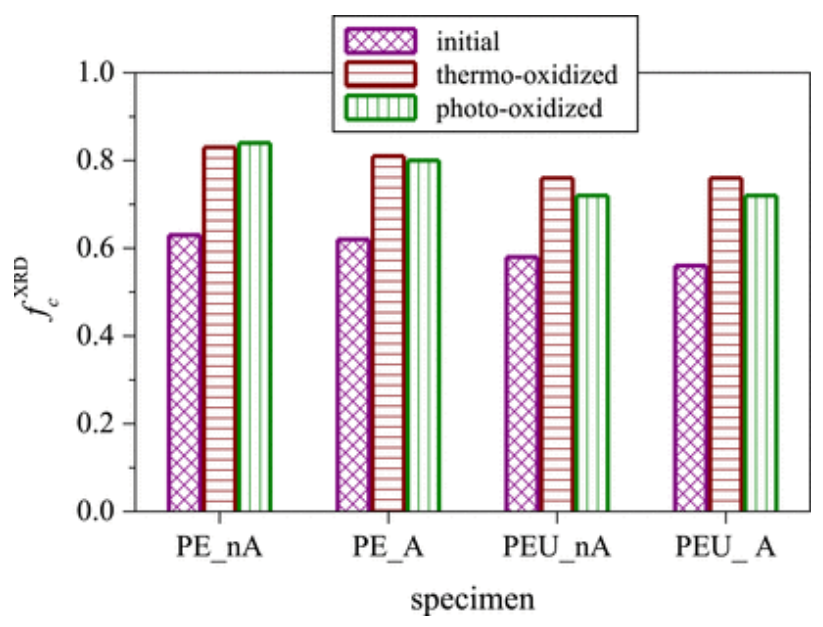

Fig. 4 Comparison of the XRD degree of crystallinity between the initial specimens and those after thermo and photo-oxidation.

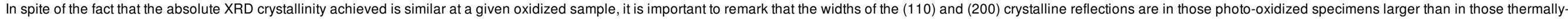
degraded samples. This fact seems to indicate that photo-oxidation leads to crystallites with a broader size distribution and, consequently, to crystalline entities with more heterogeneous heterogenus sizes.

\subsection{Time evolution of oxidation processes}

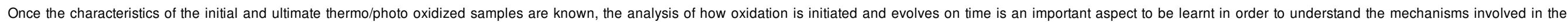

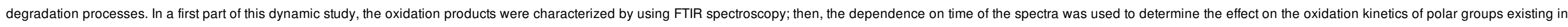




\section{elsevier_PDST_7496}

the copolymer as well as incorporation of a pro-oxidant additive. The oxidation studies were stopped when each material became very fragile, smashed and untreatable.

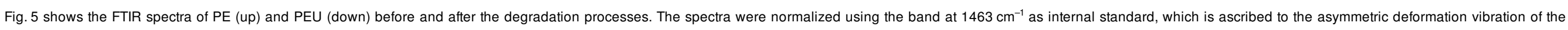

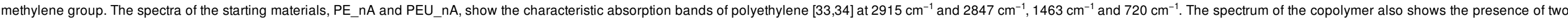

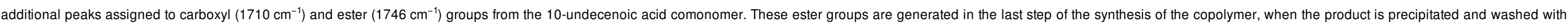

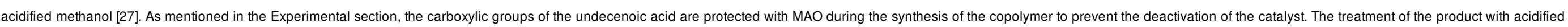

methanol allows the elimination of the aluminum bonded to the hydrophilic sites and, then, carboxyl and ester groups are generated. 


\section{elsevier_PDST_7496}
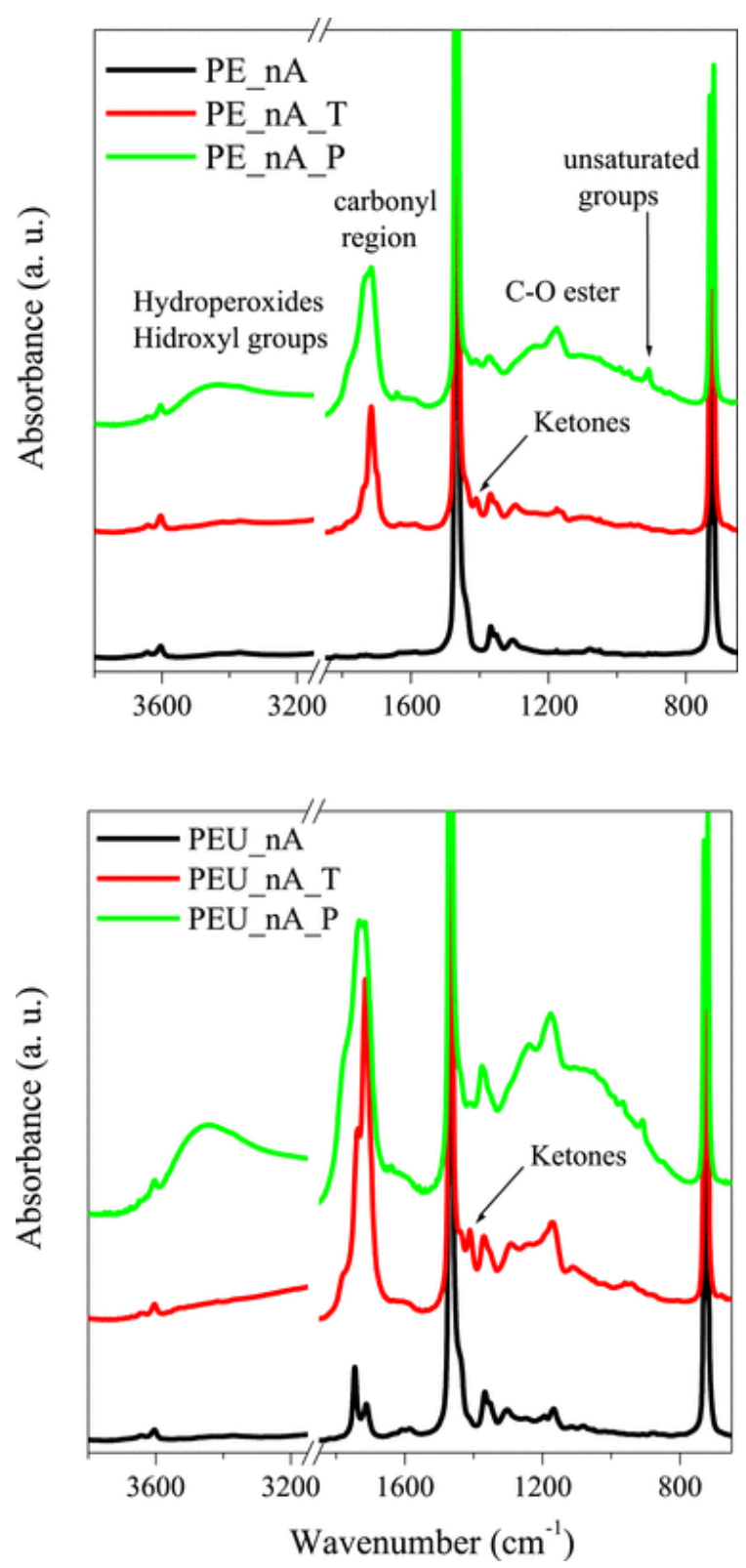

Fig. 5 FTIR spectra measured in samples before and after thermo-oxidative and photo-oxidative degradation. T and P denote thermo- and photo-oxidation, respectively.

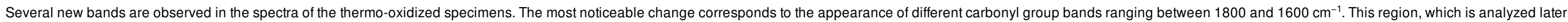
in detail, will be used to learn the effect of incorporation of 10-undecenoic acid and pro-oxidant agent in the degradation of these materials.

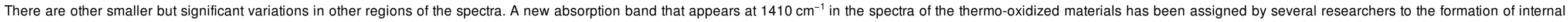

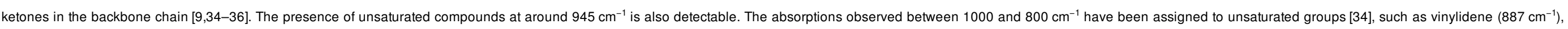




\section{elsevier_PDST_7496}

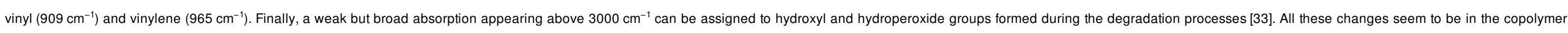
more important than in the homopolymer.

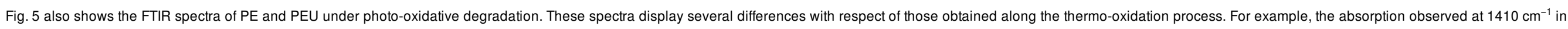

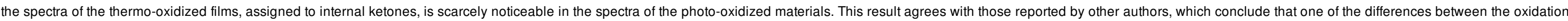

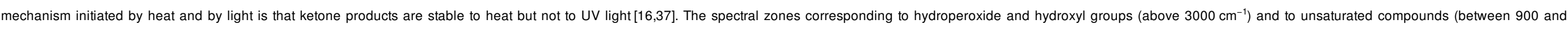
$1000 \mathrm{~cm}^{-1}$ ) reveal other variations; the absorption due to these groups is, by far, in the samples under to photo-oxidation more important than in the thermo-oxidized ones.

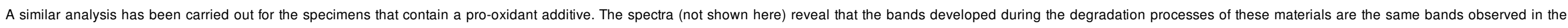
samples that do not contain the additive. None new band related to the presence of the additive was observed in the spectra of the oxidized materials.

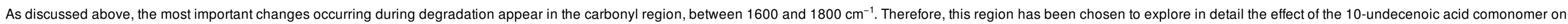

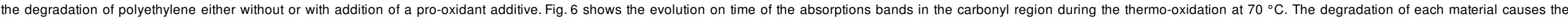

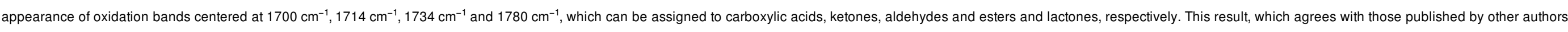

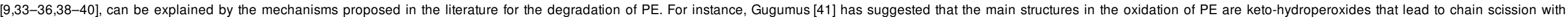

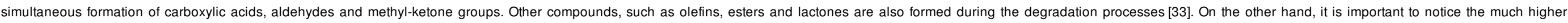
concentration of those species obtained in sample PE_A in relation to the non-additivated specimen, at similar oxidation times. 


\section{elsevier_PDST_7496}
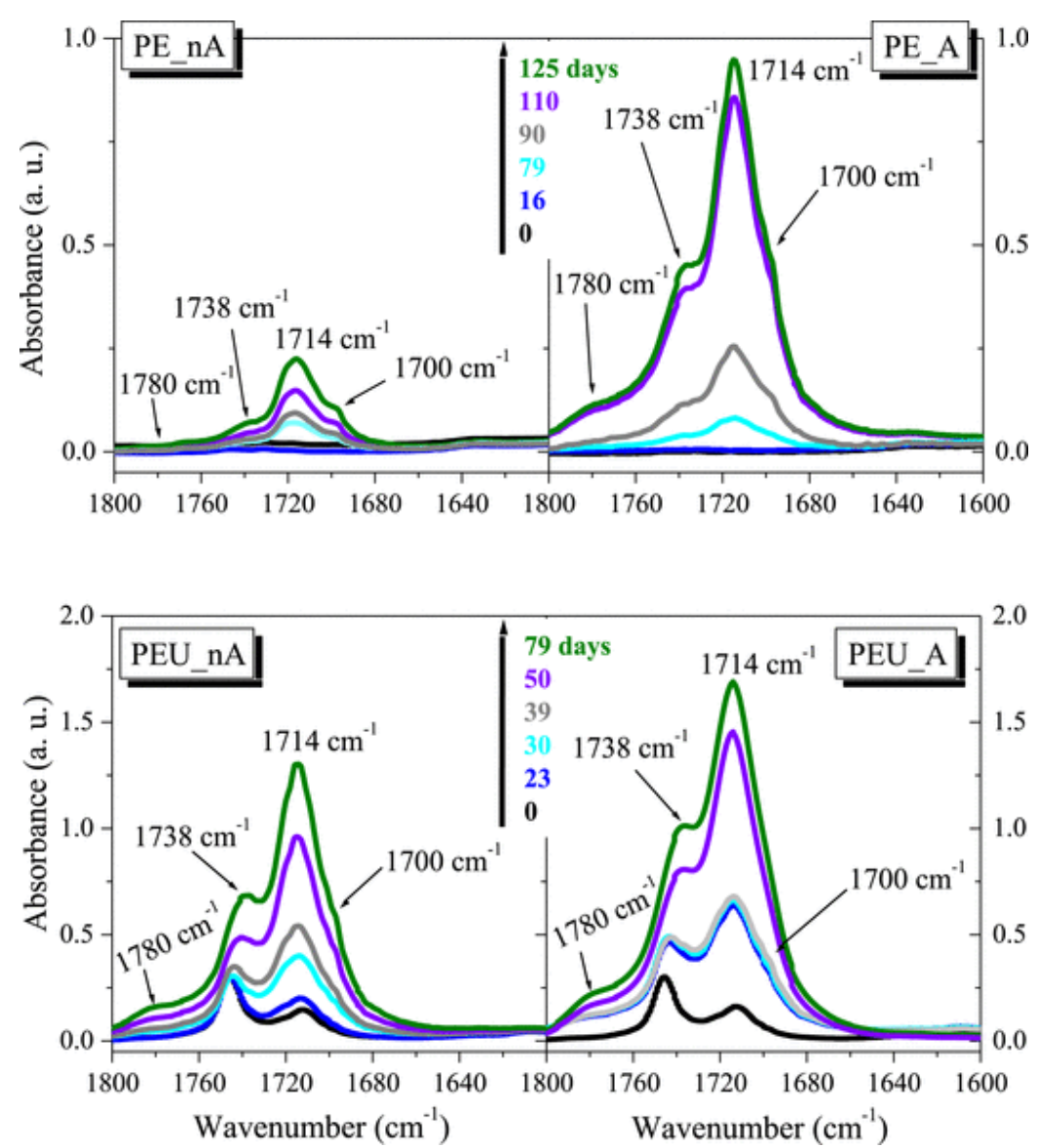

Fig. 6 Evolution of the absorption bands in the carbonyl region for the different materials during the thermo-oxidation.

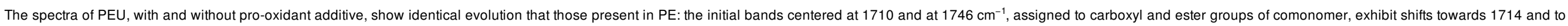

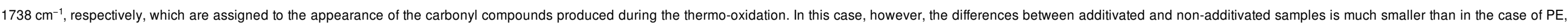
mainly because sample PEU_nA already shows a considerable enhancement of the degradation ability.

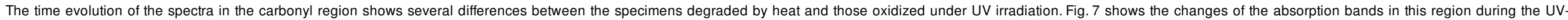

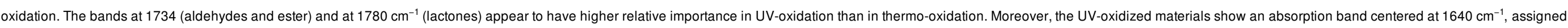

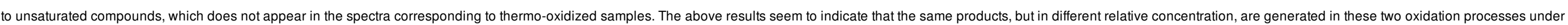
study. 
elsevier_PDST_7496
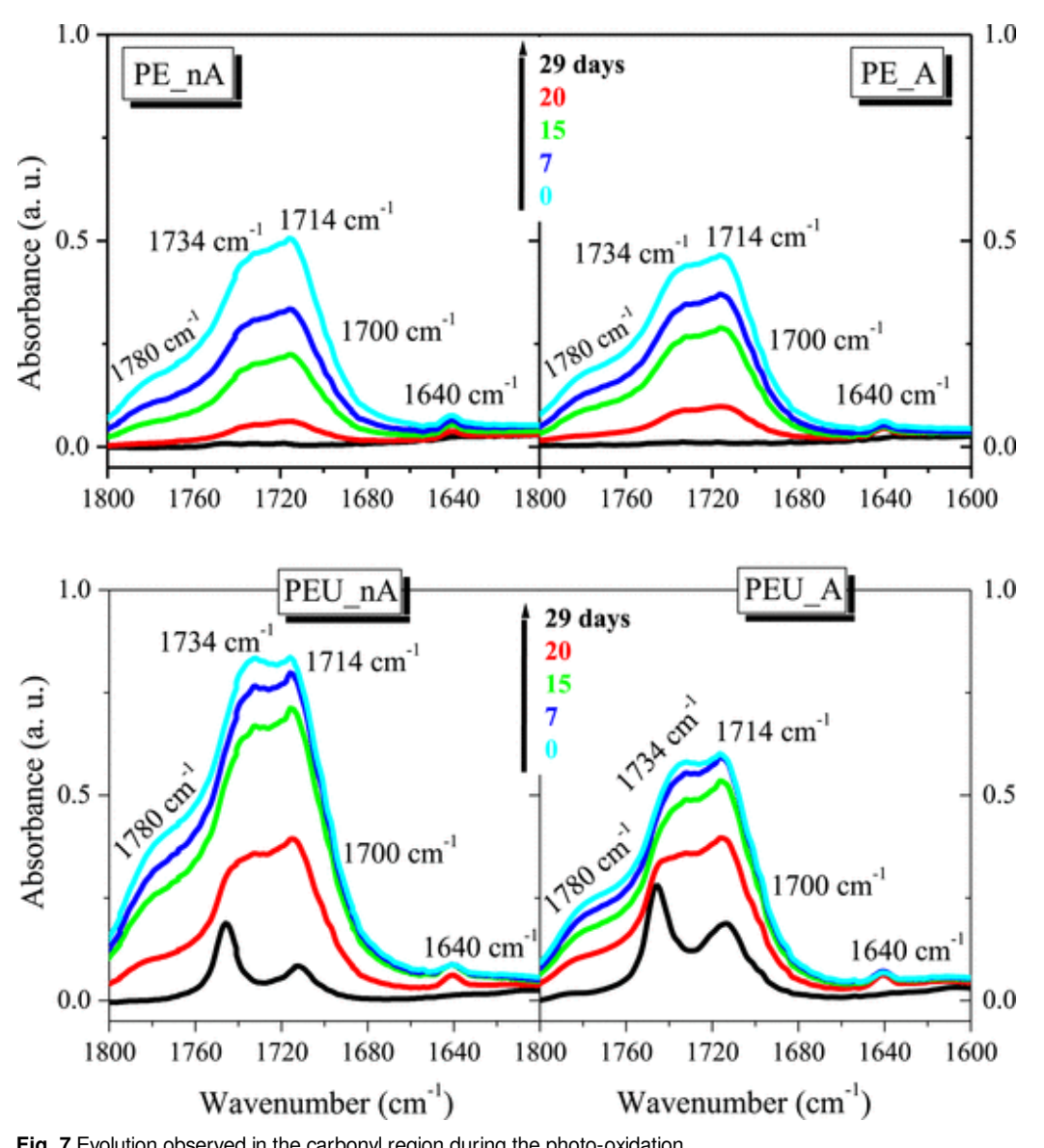

Fig. 7 Evolution observed in the carbonyl region during the photo-oxidation.

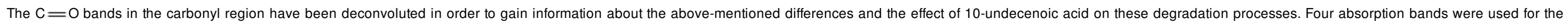

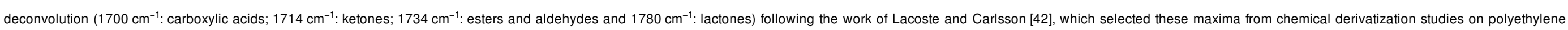

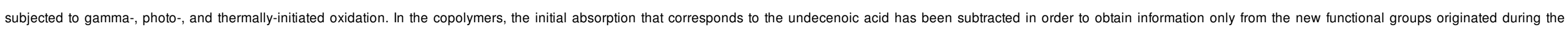
degradation processes. Fig. 8 shows the relative contributions of the resolved bands in the different specimens evaluated in this work. 


\section{elsevier_PDST_7496}

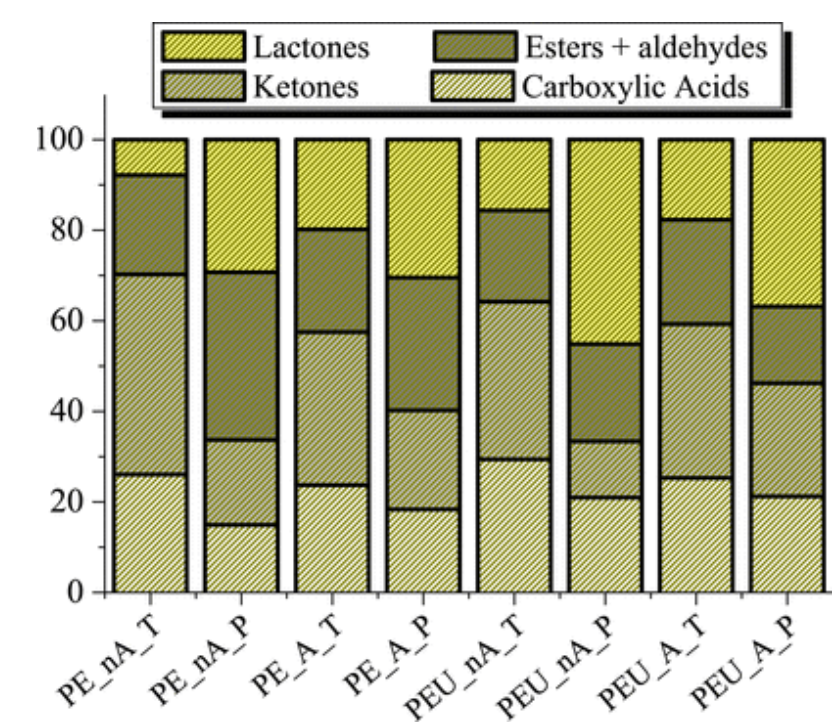

Fig. 8 Relative contributions of the four resolved bands corresponding to the carbonyl region. T and P denote thermo- and photo-oxidation, respectively.

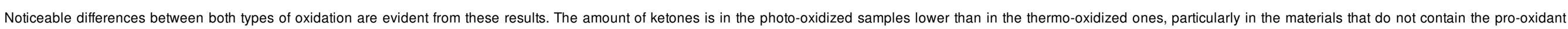

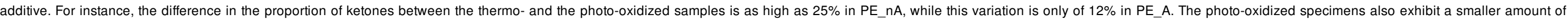

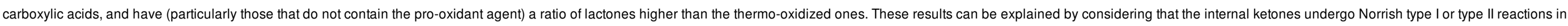

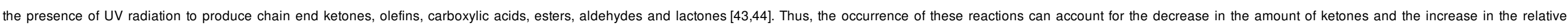

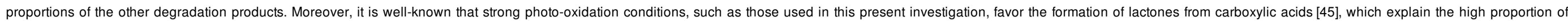
lactones (and the low amounts of carboxylic acids) found in the photo-oxidized materials.

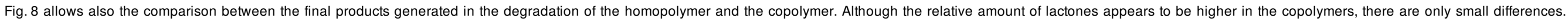
Similarly, the relative ratio of the final products is almost independent of the presence of pro-oxidant agent.

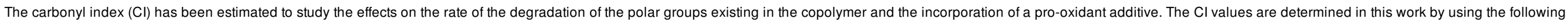
equation:

\section{$\mathrm{CI}=A_{\text {carbonyl }} / A_{1500-1424}$}

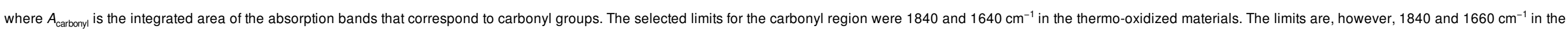

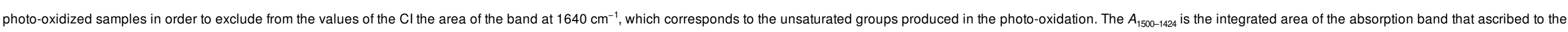
methylene groups $\left(1500=1424 \mathrm{~cm}^{-1}\right)$, used as internal reference.

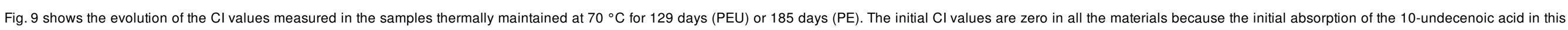
region was subtracted, in order to measure only the development of new functional groups during the degradation processes. 


\section{elsevier_PDST_7496}

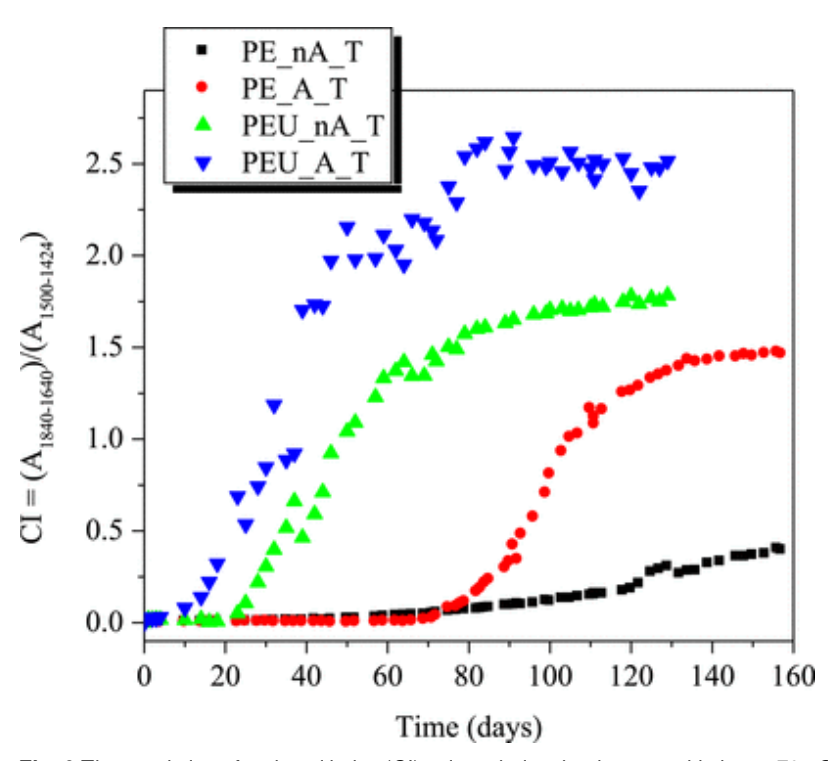

Fig. 9 Time evolution of carbonyl index (Cl) values during the thermo-oxidation at $70{ }^{\circ} \mathrm{C}$.

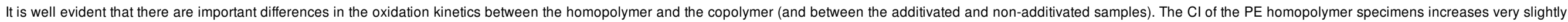

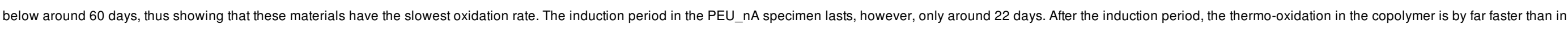
the homopolymer and the final values of the $\mathrm{Cl}$ in the time intervals studied are significantly higher in this copolymer.

Hence, it can be commented that the undecenoic acid used as comonomer speeds up the thermo-oxidation process. There are several factors that contribute to explain this feature:

- The introduction of the comonomer causes an increase of the amount of labile hydrogen atoms in tertiary carbons. This factor was also considered by Liu et al. for explaining the degradation of copolymers of ethylene and octene [33].

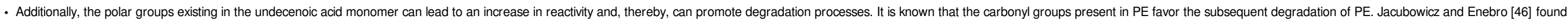
that the addition of pre-oxidized $\mathrm{PE}$ causes a significant increase in the oxidation rate of $\mathrm{PE}$.

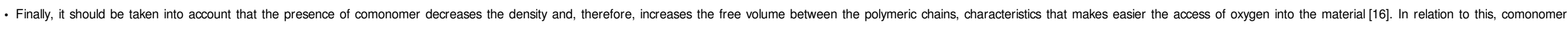

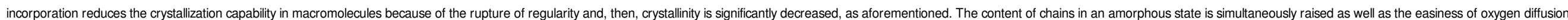
through this disordered phase.

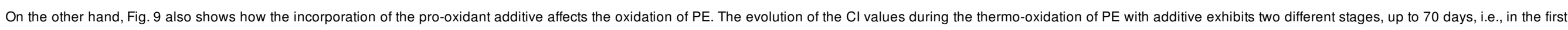

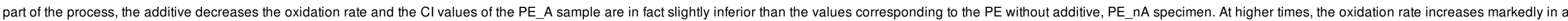

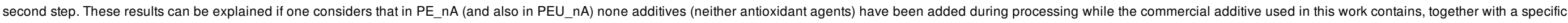

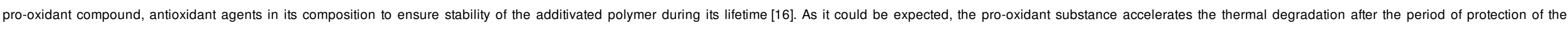

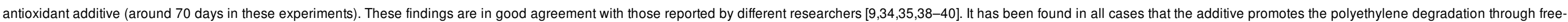
radical chain scission reactions involving the atmospheric oxygen.

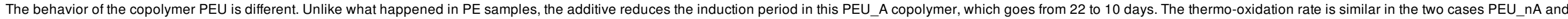

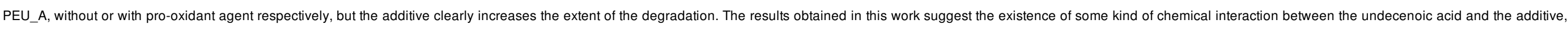
which activates the pro-oxidant action of the additive. 


\section{elsevier_PDST_7496}

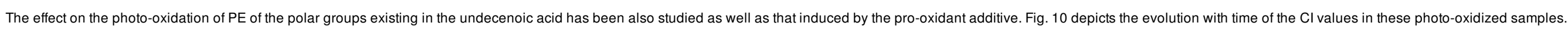

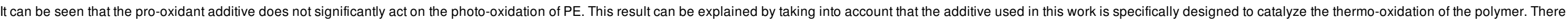
are other additives that are formulated to promote photo-oxidation processes.

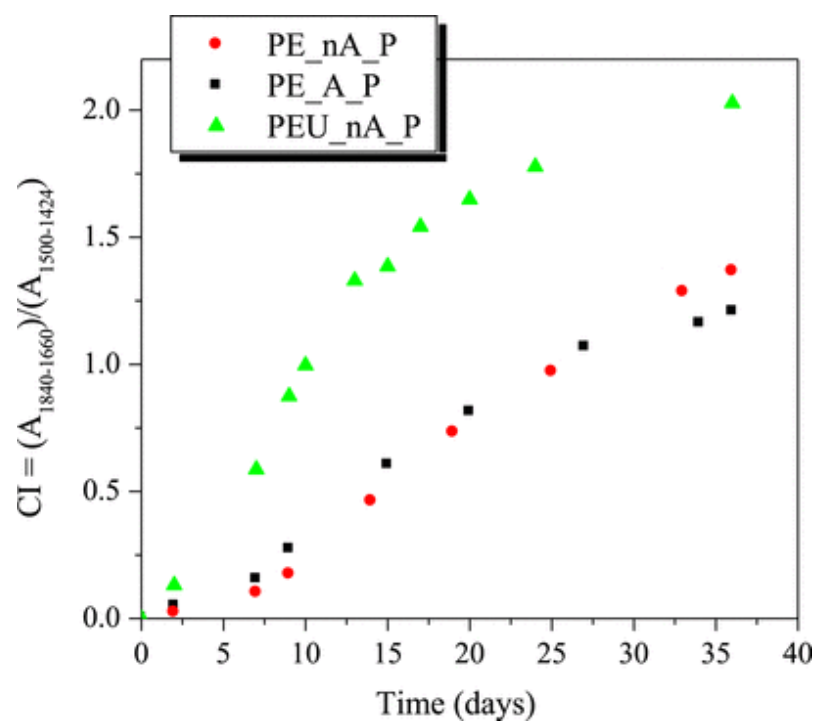

Fig. 10 Evolution on time of the carbonyl index $(\mathrm{Cl})$ values during the photo-oxidation at $35^{\circ} \mathrm{C}$.

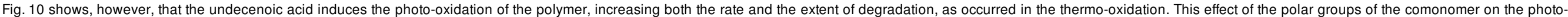
oxidation can be explained by considering the same factors that have been aforementioned in the thermo-oxidation reaction.

\subsection{Thermogravimetric analysis}

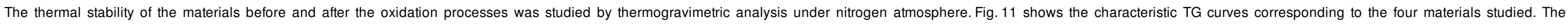

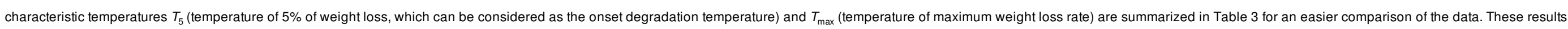

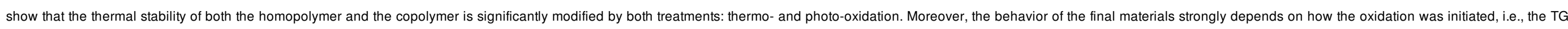
curves corresponding to thermo-oxidized materials are clearly different to those involving the photo-oxidized ones. 
elsevier_PDST_7496
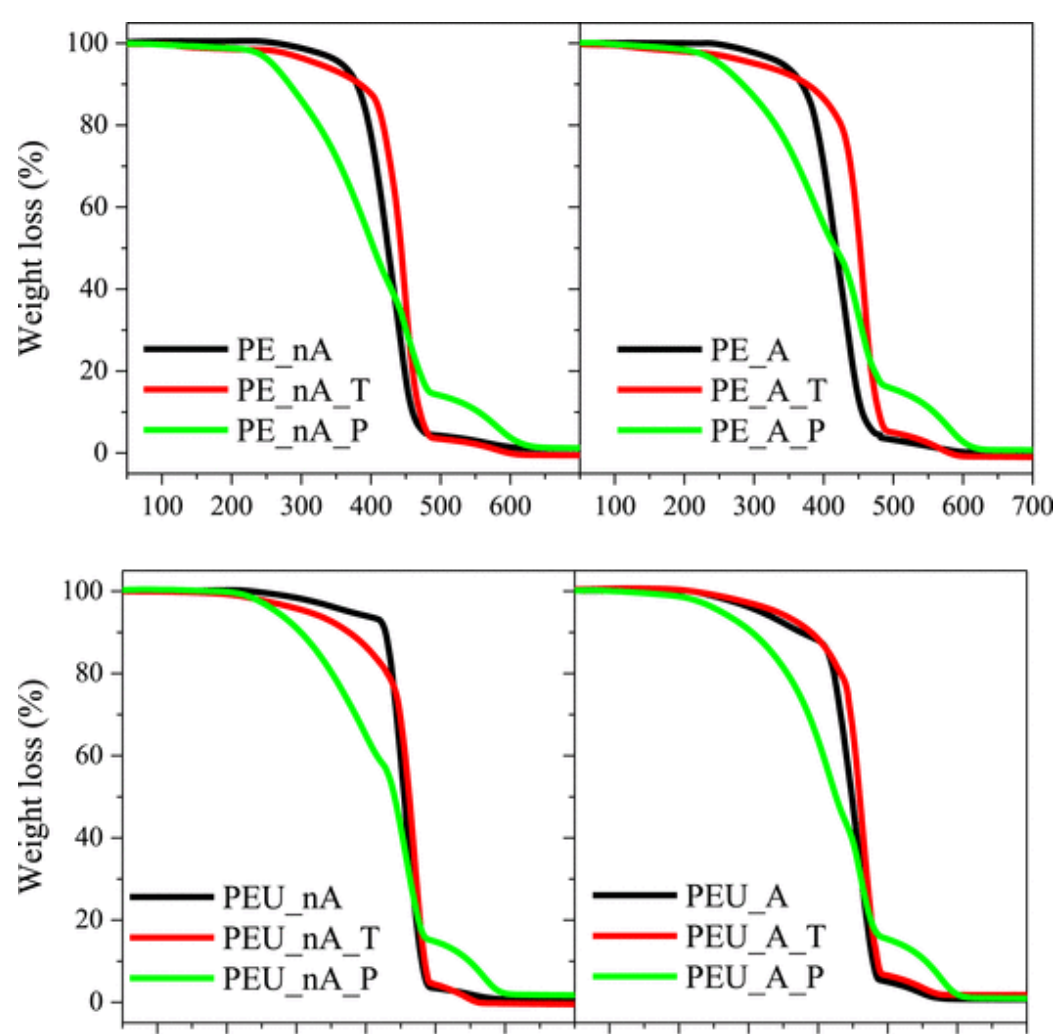

$\begin{array}{lllllllllllll}100 & 200 & 300 & 400 & 500 & 600 & 100 & 200 & 300 & 400 & 500 & 600 & 700\end{array}$

$$
\mathrm{T}\left({ }^{\circ} \mathrm{C}\right) \quad \mathrm{T}\left({ }^{\circ} \mathrm{C}\right)
$$

Fig. 11 TG curves measured before and after the oxidation processes. $T$ and $\mathrm{P}$ denote thermo- and photo-oxidation, respectively.

Table 3 Characteristic temperatures of thermal degradation of the materials before and after thermo- and photo-oxidation.

\begin{tabular}{|c|c|c|c|}
\hline & Material & $T_{5}\left({ }^{\circ} \mathrm{C}\right)$ & $T_{\max }\left({ }^{\circ} \mathrm{C}\right)$ \\
\hline \multirow[t]{3}{*}{ PE_nA } & Before degradation & 357 & 439 \\
\hline & Thermo-oxidized & 324 & 448 \\
\hline & Photo-oxidized & 258 & 448 \\
\hline \multirow[t]{3}{*}{ PEU_nA } & Before degradation & 377 & 454 \\
\hline & Thermo-oxidized & 316 & 466 \\
\hline & Photo-oxidized & 272 & 457 \\
\hline \multirow[t]{3}{*}{ PE_A } & Before degradation & 340 & 436 \\
\hline & Thermo-oxidized & 303 & 458 \\
\hline & Photo-oxidized & 251 & 451 \\
\hline PEU_A & Before degradation & 318 & 458 \\
\hline
\end{tabular}




\section{elsevier_PDST_7496}

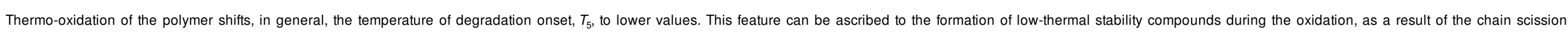

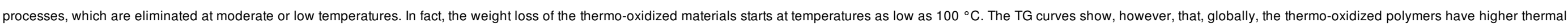

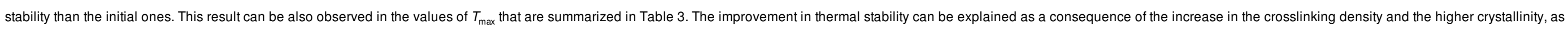
already discussed, that takes place during the thermo-oxidation. Similar enlargements in crosslinking density and crystallinity during thermo-oxidation processes are well known in other polyethylenes [47].

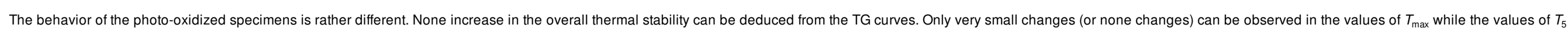

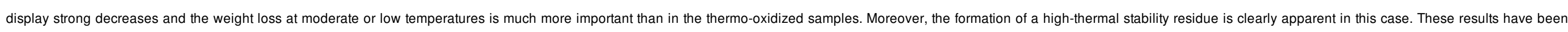
explained as consequence of a severe process of chain scission and formation of highly crosslinked structures [48], more important than the one observed during the thermo-oxidation.

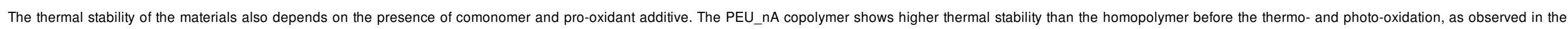

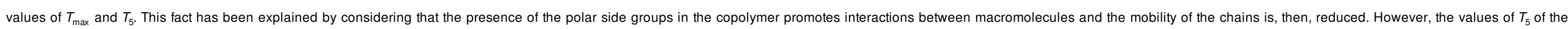

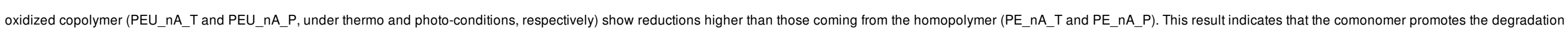
of the polymer during the oxidation processes, in good agreement with the above-mentioned results of the spectroscopic study.

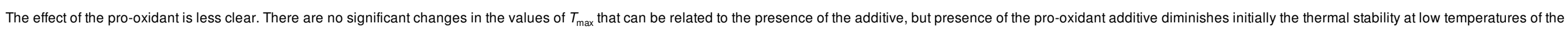

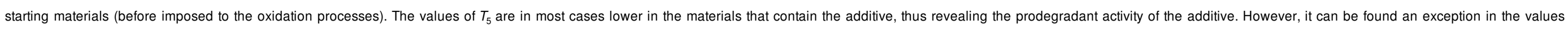
corresponding to the copolymer subjected to thermo-oxidation. In this case, $\mathrm{T}_{5}$ is higher in the material that contains the additive.

\section{Conclusions}

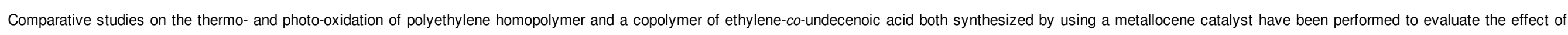
presence of the undecenoic acid on the oxidation processes. The incorporation of a small amount of a prodegradant additive was also checked.

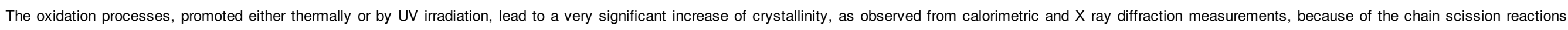
occurring within the macrochians, which take place preferentially in the amorphous regions.

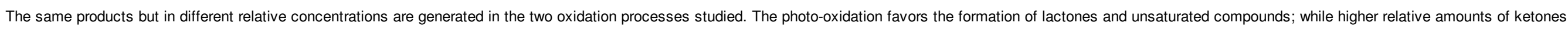

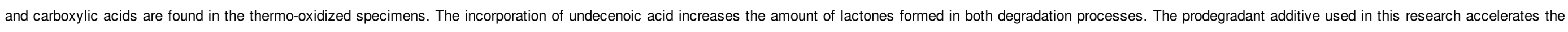

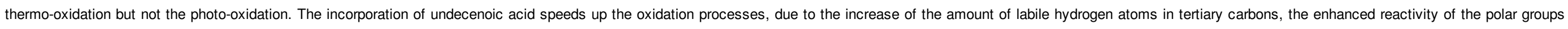

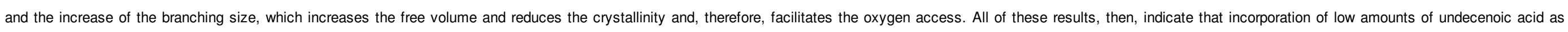
comonomer is a suitable way to control the degradation of polyethylene.

\section{AcknowledgementsAcknowledgments}

The financial support of MICINN (Project MAT2010-19883) is acknowledged as well as that received from Project CYTED 311 RT0417.

\section{References}

[1]

G. Scott, Polymers and the environment, 1999, Royal Society of Chemistry; Cambridge. 


\section{elsevier_PDST_7496}

[2]

J.E. Guillet, In: G. Scott, (Ed), Degradable polymers: principles and applications, 2nd ed., 2003, Kluwer Academic Publishers.

[3]

G. Scott and D. Gilead, In: G. Scott and D. Gilead, (Eds.), Degradable polymers: principles and applications, 1st ed., 1995, Chapman \& Hall; London.

[4]

G. Scott and D.M. Wiles, In: G. Scott, (Ed), Degradable polymers: principles and applications, 2nd ed., 2003, Kluwer Academic Publishers.

[5]

J.R. Haines and M. Alexander, Microbial degradation of polyethylene glycols, Appl Microbiol 29, 1975, 621-625.

[6]

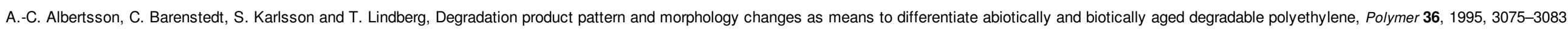

[7]

K. Yamada-Onodera, H. Mukumoto, Y. Katsuyaya, A. Saiganji and Y. Tani, Degradation of polyethylene by a fungus, Penicillium simplicissimum YK, Polym Degrad Stab 72, $2001,323-327$.

[8]

I. Jakubowicz, Evaluation of degradability of biodegradable polyethylene (PE), Polym Degrad Stab 80, 2003, 39-43.

[9]

E. Chiellini, A. Corti and G. Swift, Biodegradation of thermally-oxidized, fragmented low-density polyethylenes, Polym Degrad Stab 81, 2003, 341-351.

[10]

F. Kawai, M. Watanabe, M. Shibata, S. Yokoyama, Y. Sudate and S. Hayashi, Comparative study on biodegradability of polyethylene wax by bacteria and fungi, Polym Degrad Stab 86, 2004, 105-114.

[11]

D.M. Wiles, In: R. Smith, (Ed), Biodegradable polymers for industrial applications, 2005, Woodhead Publishing; Cambridge.

[12]

M. Scoponi, F. Pradella and V. Carassiti, Photodegradable polyolefins. Photo-oxidation mechanisms of innovative polyolefin copolymers containing double bonds, Coord Chem Rev 125, 1993, 219-230.

[13]

A.L. Andrady, J.M. Pegram and N.D. Searle, Wavelength sensitivitiy of enhanced photodegradable polethylenes, ECO, and LDPE/MX, J App/ Polym Sci 62, 1996, 1457-1463.

[14]

J.E. Guillet, Photodegradable polymer compositions comprising blends of polymers with ketone containing block or graft copolymers, Pat US4176145, assigned to Guillet JE1979.

[15]

P.J. Modi and J.E. Guillet, The photochemistry of polymers containing anthrylmethyl vinyl ketone, J Polym Sci Pol Chem 33, 1995, 197-201.

[16]

A. Ammala, S. Bateman, K. Dean, E. Petinakis, P. Sangwan, S. Wong, et al., An overview of degradable and biodegradable polyolefins, Prog Polym Sci 36, 2011, 1015-1049.

[17]

G. Scott, Polym Degrad Stab 68, 2000, 1-7. 


\section{elsevier_PDST_7496}

[18]

(a) U. Giannmni, G. Bruckner, E. Pellino and A. Cassata, Polymerization of nitrogen-containing and oxygen-containing monomers by Ziegler-Natta catalysts, J Polym Sci Part C Polym Symp 22, 1968, 157;

(b) C.G. Overberger and G. Khattab, J Polym Sci Part A-I 7, 1969, 217;

(c) M.D. Purgett and O. Vogl, J Polym Sci Polym Chem Ed 27, 1989, 2051.

[19]

M. Xanthos, Reactive extrusion. Principles and practice, 1992, Hanser Publishers; New York.

\section{[20]}

(a) T.C. Chung, Synthesis of polyalcohols via ziegler-natta polymerization, Macromolecules 21, 1988, 865-869;

(b) T.C. Chung, M. Raate, E. Berluche and D.N. Schulz, Synthesis of functional hydrocarbon polymers with well-defined molecular structures, Macromolecules 21, 1988, 1903-1907;

(c) S. Ramakrishnan, E. Berluche and T.C. Chung, Functional-group containing copolymers prepared by the Ziegler-Natta process, Macromolecules 23, 1990, 378-382;

(d) T.C. Chung and D. Rhubright, Synthesis of functionalized polypropylene, Macromolecules 24, 1991, 970-972;

(e) T.C. Chung and D. Rhubright, Functionalization of polypropylene by hydroboration, J Polym Sci Part A Polym Chem 31, 1993, 2759-2763;

(f) T. Shiono, H. Kurosawa, O. Ishida and K. Soga, Synthesis of polypropylenes functionalized with secondary amino groups at the chain ends, Macromolecules 26, 1993, 2085-2089;

(g) T.C. Chung, H.L. Lu and C.L. Li, Synthesis and functionalization of unsaturated polyethylene - poly(ethylene-co-1,4-hexadiene), Macromolecules 27, $1994,7533-7537$.

[21]

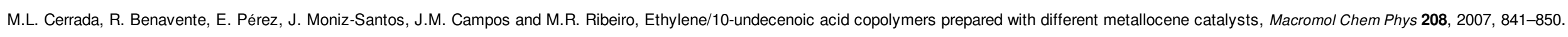

\section{[22]}

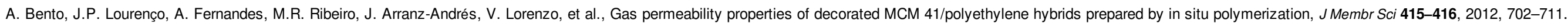

[23]

M.L. Cerrada, E. Pérez, J.P. Lourenço, A. Bento and M.R. Ribeiro, Decorated MCM-41/polyethylene hybrids: crystalline details and viscoelastic behavior, Polymer 54, 2013, 2611-2620.

[24]

J. Arranz-Andrés, V. Lorenzo, M.U. de la Orden, E. Pérez and M.L. Cerrada, Tailoring transport properties in blends based on olephinic and liquid crystalline polymers, J Membr Sci 377, 2011, 141-150.

[25]

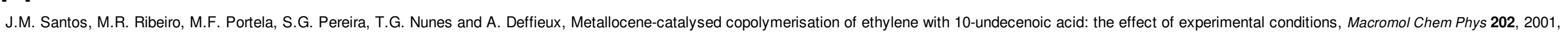
2195-2201.

[26]

F.A. Quinn and L. Mandelkern, Thermodynamics of crystallization in high polymers-poly-(ethylene), J Am Chem Soc 80, 1958, 3178-3182.

[27]

B. Wunderlich, Macromolecular physics, 1980, Academic Press; New York.

[28]

R.G. Alamo, B.D. Viers and L. Manderkern, Phase-structure of random ethylene copolymers - a study of counit content and molecular-weight as independent variables, Macromolecules 26, $1993,5740-5747$.

[29]

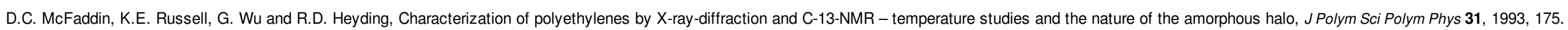




\section{elsevier_PDST_7496}

[30]

J. Minick, A. Moet, A. Hiltner, E. Baer and S.P. Chum, Crystallization of very low-density copolymers of ethylene with alpha-olefins, J Appl Polym Sci 58, $1995,1371$.

[31]

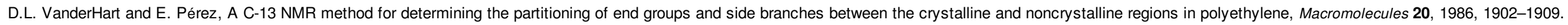

[32]

E. Pérez, D.L. VanderHart, B. Crist and P.R. Howard, Morphological partitioning of ethyl branches in polyethylene by C-13 nuclear magneticresonance, Macromolecules 21, 1987, 78-87.

[33]

Z. Liu, S. Chen and J. Zhang, Photodegradation of ethylene-octene copolymers with different octene contents, Polym Degrad Stab 96, 2011, $1961-1972$.

[34]

A. Benítez, J.J. Sánchez, M.L. Arnal, A.J. Müller, O. Rodríguez and G. Morales, Abiotic degradation of LDPE and LLDPE formulated with a pro-oxidant additive, Polym Degrad Stab 98, 2013 , 490-501.

[35]

P.K. Roy, P. Surekha, C. Rajagopal, S.N. Chatterjee and V. Choudhary, Accelerated aging of LDPE films containing cobalt complexes as prooxidants, Polym Degrad Stab $91,2006,1791-1799$.

[36]

P.K. Roy, P. Surekha, C. Rajagopal, S.N. Chatterjee and V. Choudhary, Studies on the photo-oxidative degradation of LDPE films in the presence of oxidised polyethylene, Polym Degrad Stab 92, 2007, 1151-1160.

[37]

D.M. Wiles and G. Scott, Polyolefins with controlled environmental degradability, Polym Degrad Stab 91, 2006, 1581-1592.

[38]

M.M. Reddy, R.K. Gupta, R.K. Gupta, S.N. Bhattacharya and R. Parthasarathy, Abiotic oxidation studies of oxo-biodegradable polyethylene, J Polym Environ 16, $2008,27-34$.

[39]

E. Chiellini, A. Corti, S. D'Antone and R. Baciu, Oxo-biodegradable carbon backbone polymers - oxidative degradation of polyethylene under accelerated test conditions, Polym Degrad Stab 91, 2006, 2739-2747.

[40]

X. Liu, Ch Gao, P. Sangwan, L. Yu and Z. Tong, Accelerating the degradation of polyolefins through additives and blending, J Appl Polym Sci 131, 2014, 407-450.

[41]

F. Gugumus, Re-examination of the thermal oxidation reaction of polymers 3. Various reactions in polyethylene and polypropylene, Polym Degrad Stab 77, $2002,147-155$.

[42]

J. Lacoste and D.J. Carlsson, Gamma-, photo-, and thermally-initiated oxidation of linear low density polyethylene: a quantitative comparison of oxidation products, J Polym Sci Part A Polym Chem 30 (3), $1992,493-500$.

[43]

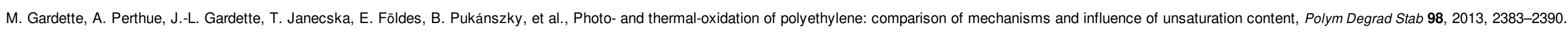

[44]

M. Bertoldo, S. Bronco, Ch Cappelli, T. Gragnoli and L. Andreotti, Combining theory and experiment to study the photooxidation of polyethylene and polypropylene, J Phys Chem B 107, 2003, 11880-11888.

[45]

A. Valadez-González, J.M. Cervantes-Uc and L. Veleva, Mineral filler influence on the photo-oxidation of high density polyethylene: I. Accelerated UV chamber exposure test, Polym Degrad Stab 63, 1999, 253-260. 


\section{elsevier_PDST_7496}

[46]

I. Jakubowicz and J. Enebro, Effects of reprocessing of oxobiodegradable and non-degradable polyethylene on the durability of recycled materials, Polym Degrad Stab 97, 2012, 316-321.

[47]

J-II Weon, Effects of thermal ageing on mechanical and thermal behaviors of linear low density polyethylene pipe, Polym Degrad Stab 95, 2010, 14-20.

[48]

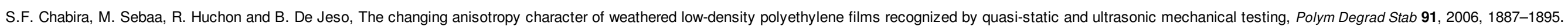

\section{Queries and Answers}

Query: Please check the country name introduced in affiliation "b" and correct if necessary.

Answer: Te affiliation $b$ is accurate

Query: Please check the designated corresponding authors and correct if necessary.

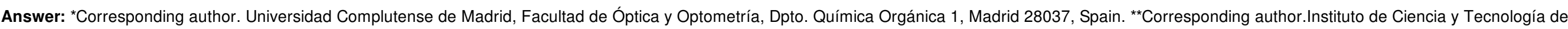
Polímeros (ICTP-CSIC), 28006 Madrid, Spain

Query: As Refs. [9] and [36] were identical, the latter has been removed from the reference list and subsequent references have been renumbered. Kindly check and correct if necessary.

Answer: OK. We agree

Query: Please confirm that given names and surnames have been identified correctly.

Answer: Te surname of J. Martínez Urreaga is Martínez Urreaga. 